\title{
Noncompaction cardiomyopathy, mitral valve prolapse and bicuspidal aortic valve in a 22-year-old men - case report
}

Vesna Pehar-Pejčinović ${ }^{1 *}$, Viktor Peršić1, Marko Boban1, Aleksandra Šustar, Dijana Travica Samsa', Marijana Rakić', Damir Raljević', Dragan Javoran', Rajko Miškulin²

${ }^{1}$ Thalassotherapia Opatija - Clinic for treatment, rehabilitation and prevention of cardiovascular disease, Opatija, Croatia

${ }^{2}$ University of Rijeka School of Medicine, University Hospital Centre Rijeka, Rijeka, Croatia

Left ventricular noncompaction is a rare congenital cardiomyopathy which is characterized by the presence of a thin, compacted epicardial layer and a non-compacted thicker endocardial layer of the myocardium, with prominent trabeculation and deep recesses communicating with the cavity of the left ventricle.

The American Heart Association classifies noncompaction cardiomyopathy as a genetic cardiomyopathy, while the European Society of Cardiology considers noncompaction cardiomyopathy as an unclassified cardiomyopathy. The prevalence of this cardiomyopathy is about $0.014-1 \%$ in the general population. Noncompaction of the left ventricle probably results from an improper development of the myocardium in 3-8 week of intrauterine life.

\section{Received: $18^{\text {th }}$ Apr 2014}

*Address for correspondence: Thalassotherapia Opatija, Maršala Tita 188/1, HR51410 Opatija, Croatia.

Phone: +385-51-202-724

E-mail: pehar.vesna@gmail.com
The clinical picture varies from mild forms to severe forms with heart failure, complex ventricular arrhythmias and thromboembolic incidents. It can exist in an isolated form or is associated with other congenital cardiac and neuromuscular diseases. Left ventricular noncompaction is reported to be highest among the patients with Ebstein's anomaly, tetralogy of Fallot, malformation of the left ventricle outflow tract including unicuspid and bicuspid aortic valve and aortic coarctation.

In our case report, we are presenting a young male, 22 years old where we made the diagnosis of noncompaction cardiomyopathy associated with bicuspidal aortic valve and mitral valve prolapse using the imaging method of echocardiography and cardiac MRI.

KEYWORDS: noncompaction cardiomyopathy, bicuspidal aortic valve, mitral valve prolapse.

CITATION: Cardiol Croat. 2014;9(5-6):200.

\section{Literature}

1. Agarwal A, Khandheria BK, Paterick TE, Treiber SC, Bush M, Tajik AJ. Left ventricular noncompaction in patients with bicuspid aortic valve. J Am Soc Echocardiogr. 2013;11(26):1306-13.

2. Thavendiranathan P, Dahiya A, Phelan D, Desai MY, Tang WH. Isolated left ventricular non-compaction controversies in diagnostic criteria, adverse outcomes and management. Heart. 2013;99(10):681-9.

3. Stähli BE, Gebhard C, Biaggi P, et al. Left ventricular non-compaction: prevalence in congenital heart disease. Int J Cardiol. 2013;167(6):2477-81. 